\title{
Féeries
}

Études sur le conte merveilleuX, XVII ${ }^{e}$ XIXe siècle

\section{Roxane Martin, La Féerie romantique sur les scènes parisiennes (1791-1864), Champion, 2007, 693 p.}

\section{Christelle Bahier-Porte}

\section{(2) OpenEdition}

1 Journals

\section{Édition électronique}

URL : http://journals.openedition.org/feeries/690

DOI : $10.4000 /$ feeries.690

ISSN : 1957-7753

Éditeur

UGA Éditions/Université Grenoble Alpes

\section{Édition imprimée}

Date de publication : 1 juin 2008

Pagination : 164-168

ISBN : 978-2-84310-123-6

ISSN : 1766-2842

\section{Référence électronique}

Christelle Bahier-Porte, "Roxane Martin, La Féerie romantique sur les scènes parisiennes (1797-1864), Champion, 2007, 693 p. », Féeries [En ligne], 5 | 2008, mis en ligne le 01 septembre 2009, consulté le 24 septembre 2020. URL : http://journals.openedition.org/feeries/690 ; DOI : https://doi.org/10.4000/ feeries.690

Ce document a été généré automatiquement le 24 septembre 2020.

\section{(c) Féeries}




\title{
Roxane Martin, La Féerie romantique sur les scènes parisiennes (1791-1864), Champion, 2007, $693 \mathrm{p}$.
}

\author{
Christelle Bahier-Porte
}

1 Cet ouvrage est le fruit du remaniement d'une thèse soutenue en 2003 sous la direction de Jean-Marie Thomasseau. Il se donne pour objet l'étude d'un genre méconnu et jamais étudié avec une telle précision: la féerie théâtrale au dix-neuvième siècle, à partir d'un corpus impressionnant de près de 700 pièces et de 1500 documents (partitions, livrets de mise en scène, comptes rendus de censure). Alors que l'on ne retient souvent de l'histoire du théâtre du $\mathrm{xIX}^{\mathrm{e}}$ siècle que le drame romantique, la féerie est, avec le vaudeville et le mélodrame, une des formes les plus vivantes et les plus représentées sur les différentes scènes parisiennes. Le travail de Roxane Martin rend admirablement compte de la vitalité et de la pérennité d'une forme qui, nous semble-t$\mathrm{il}$, trouve ses racines dans le théâtre du merveilleux de la fin du XVII et du XvIII siècle, abordé dans le numéro 4 de la revue Féeries. L'étude proposée commence en 1791, date de l'abolition des privilèges dramatiques et s'achève en 1864 qui marque le début de la liberté industrielle des théâtres.

Le premier problème posé par l'auteur est celui de la définition même du "genre» de la féerie théâtrale. Elle refuse de le définir uniquement à partir de ses thèmes de prédilection: le merveilleux et le spectaculaire, car d'autres genres comme la comédie, le ballet, la pantomime puisent dans le registre du merveilleux. Elle refuse également de définir la féerie comme «simple conte de fées mis à la scène» (p. 13) et de considérer la féerie comme "genre dramatique autonome» avant la fin du xviIIesiècle. Dans le détail de l'analyse, on comprend la difficulté. Il apparaît en fait que jusqu'aux années 1830 , le «genre» en question n'est pas véritablement codifié. Il reste proche des autres formes théâtrales en vogue, auxquelles il emprunte volontiers: le vaudeville, l'opéra ou encore la pantomime ou le mélodrame. L'auteur en vient alors à se demander si la féerie ne serait pas moins un "genre» qu'une "catégorie esthétique» (p. 169) dont le seul critère fiable serait la parenté avec le conte merveilleux (ses personnages 
notamment). En revanche, à partir des années 1830, on peut trouver des traits définitoires plus nets, sans doute à la faveur d'une certaine «mécanisation» du genre. L'appellation «féeries romantiques» aurait par ailleurs pu être précisée, même si l'auteur prend soin «pour écarter tout débat» (p. 16) de faire du «romantisme» une catégorie transhistorique. Outre cette problématique du genre, la thèse principale, développée et précisée tout au long de l'ouvrage, est le primat de la «mise en scène» et du spectaculaire sur le texte dans ce genre de théâtre. Il s'agit pour l'auteur de décrire le passage d'une «esthétique du texte à une poétique de la scène» (p.18) et de mettre en avant le rôle d'une forme dite "populaire» dans la réforme de l'écriture théâtrale du xIxesiècle.

3 L'ouvrage se compose de deux parties chronologiques, la première partie - «La féerie au cœur des genres» - s'intéresse à la période 1791-1830 et la seconde - «Une esthétique du spectaculaire» - est consacrée aux années 1831-1864 qui voient l'avènement $d u$ «tableau» comme unité dramaturgique du genre. L'analyse chronologique sait aussi ménager des passages plus synthétiques (par exemple sur les notions de merveilleux, féerique, fantastique ou encore sur le tableau, le comique) et des analyses précises de pièces particulièrement représentatives de chaque période ( $L e$ Pied de Mouton, 1806; Les Petites Danaïdes, ou 99 victimes, 1819; Les Pilules du diable, 1839; Les Mille et Une Nuits, 1843 etc.).

4 À la fin du XVIII ${ }^{e}$ siècle, le «genre» de la féerie ne se laisse pas facilement circonscrire et l'auteur, malgré ses réticences, doit revenir à des critères thématiques: présence d'un personnage de fée ou d'une intrigue de conte merveilleux (puisée dans LeCabinet des fées ou les contes bleus), défense d'une certaine morale du sentiment et du mérite (qualifiée de «romantique»? p. 32). Il apparaît néanmoins que l'intrigue se fonde durablement sur le schéma d'une quête, amoureuse et initiatique et sur le "grand spectacle», en particulier les «clous». Dès le Consulat, on observe une certaine «mécanisation de la fable»: un génie protecteur, une quête, un talisman, le combat entre puissances du bien et du mal deviennent les passages obligés de toute féerie. On note également que, dès le Consulat et les premiers succès des féeries, la parodie s'impose comme élément constitutif du genre, ce qui était déjà le cas pour le conte littéraire et les pièces «féeriques» des siècles précédents.

5 Entre 1807 et 1830, le conte reste la source d'inspiration principale des féeries, avec près d'un tiers des pièces jouées se référant plus ou moins aux contes de Perrault. Les formes sont encore diverses et composites (l'opéra-féerie et ses parodies, le balletféerie). Tous les théâtres accueillent néanmoins ce type de pièces de l'Opéra au Boulevard dont les différents théâtres hésitent entre deux types de féeries: la féérie morale héritée du Consulat, qui devient «manichéenne» et moralisatrice sous la Restauration sous l'égide notamment de Pixérécourt et une féerie plus grotesque ou «burlesque» privilégiant les situations comiques et l'autodérision. La codification du genre se précise alors à partir des années 1830: la féerie se fonde sur une quête amoureuse, adopte une composition en tableaux de plus en plus autonomes lesquels permettent d'une part de "poser les conventions du monde féerique» ou de mettre en avant la leçon morale et d'autre part de confirmer l'orientation purement visuelle d'un spectacle se muant en art «oculaire» et pratiquant volontiers la surenchère. Dans les années 1840, l'invention d'un prologue dont le but est de présenter la quête et d'exposer le conflit permet ensuite aux tableaux de se dérouler un à un avec leur décor 
et leur thème propres. Cette structure figée autorise la multiplication des numéros scéniques, des chants, de la danse visant la fascination du spectateur.

Dans les années 1850 et 1860, c'est l'ère de «l'industrialisation du genre» (p. 345), essentiellement sur les petites scènes. L'auteur distingue alors de nouveau deux types de féeries, qui semblent en fait rendre compte des deux pôles du théâtre du merveilleux tel qu'il est pratiqué dès la fin du XVII siècle: le spectacle et la dérision. Les grands théâtres du Boulevard privilégient le faste de la mise en scène avec des représentations qui durent plus de quatre heures, tandis que les petits théâtres favorisent une veine parodique et comique, n'hésitant pas à reprendre les «clous» et autres refrains des pièces à succès. Cette pratique de la caricature conduit l'auteur à examiner les principes d'un «comique féerique» qui repose pour beaucoup sur les effets de mise en scène, dont certains auraient pu être rapprochés des lazzis de la commedia dell'arte. Sur le plan verbal, le comique repose sur l'onomastique, mais là encore c'est un trait définitoire du conte en premier lieu puis des adaptations scéniques des siècles précédents: les Princes et Princesses Chagrinant, Abricotine, Nonchalante ou Babillarde trouvent leurs aînés chez les premières conteuses.

7 Les jeux de mots et calembours abondent par ailleurs pour susciter le rire du public. Cette période permet également aux lecteurs de découvrir les tentatives féeriques de «grands» écrivains: Victor Hugo aurait collaboré à l'écriture d'un spectacle intitulé Le Ciel et l'Enfer (1853), Flaubert a laissé plusieurs manuscrits féeriques, étudiés de près par Roxane Martin.

8 Le parcours est donc très riche en découvertes et appuyé sur un corpus parfaitement maîtrisé, inédit et rendu très accessible par l'analyse qui en est proposée. On peut néanmoins regretter, même si cela est très compréhensible dans une thèse fondée sur un grand nombre de documents, une moindre connaissance des pièces à sujets merveilleux des siècles précédents et du conte littéraire qui les a inspirées. L'auteur entend certes distinguer le «féerique» dont relèveraient les pièces des siècles précédents et la "féerie» en tant que genre constitué, mais on aurait aimé plus de précisions dans cette distinction. Certaines affirmations auraient ainsi pu être plus nuancées: peut-on dire que c'est seulement avec les féeries des années 1790 que l'on rompt «ouvertement avec le système des unités classiques» (p. 39)? Une référence sibylline au "genre de Lesage» (p.139) désigne, semble-t-il, l'ensemble des opérascomiques du xviIIesiècle. Doit-on attendre 1860 pour comprendre que «la représentation féerique n'est plus fondée sur le concept de vraisemblance» et que l'on peut «construire une fiction à l'aide de la mise en mouvement de la matière dramatique elle-même» (p.457)? Peut-on dire que le «théâtre du xix siècle a découvert les prestiges de la mise en scène» (p. 475), ou même son «pouvoir parodique et comique»? Il me semble que toutes ces caractéristiques se mettent en place au cours des XVII et $\mathrm{XVIII}^{\mathrm{e}}$ siècles, qu'elles doivent par ailleurs beaucoup à une certaine conception du conte merveilleux qui reste, comme le montre très bien l'ouvrage, une référence constante.

On notera également un usage un peu hasardeux et parfois arbitraire du terme «esthétique»: «esthétique du texte», «esthétique du burlesque», «esthétique de la démesure et du débord», «esthétique de l'hypertrophie», «esthétique du loufoque et de la cocasserie», «esthétique de la parodie».

10 Il faut souligner, pour finir, la richesse des annexes, qui sont une véritable mine d'or pour le chercheur et l'amateur de théâtre un peu curieux. Outre des index et une très riche bibliographie, on trouve en effet à la fin du volume, un «répertoire 
bibliographique des pièces et des documents relatifs à leurs représentations» décliné en six chapitres: un classement des 666 pièces dépouillées par titre, une liste des documents iconographiques disponibles, une liste des partitions musicales et de tous les documents liés à la mise en scène (livrets, couplets, rapports de censure). Le dernier chapitre donne la liste des pièces par ordre chronologique des représentations, accompagnée d'utiles notes portant sur la musique, la mise en scène ou les reprises des pièces. En effet, outre un intérêt historique indéniable, cette thèse a également pour mérite de proposer une méthodologie fondée sur le croisement des sources et la prise en compte constante et sans préjugé aucun de l'art du spectacle (voir par exemple les tableaux des pages 73-99 et 304-324 qui opèrent de véritables reconstitutions des spectacles tels qu'ils ont pu être joués). Indéniablement, l'auteur a su rendre compte de cette "poétique de la scène», caractéristique de la féerie théatrale. 